\title{
Importance of training the personnel performing specific activities related to equipment I installations operating in areas classified as with potentially explosive atmospheres
}

\author{
Lucian Moldovan ${ }^{1 *}$, Mihai Magyari ${ }^{1}$, Adriana Andriș ${ }^{1}$, Gabriela Pupăzan ${ }^{1}$, \\ Clementina Moldovan ${ }^{2}$ \\ ${ }^{1}$ National Institute for Mine Safety and Protection to Explosion - INSEMEX, Department for Safety \\ of Installations and Explosion-proof Equipment, 32-34 G-ral Vasile Milea, Petrosani, Romania \\ ${ }^{2}$ University of Petrosani, Department of Environmental Engineering and Geology, 20 University \\ street, Petrosani, Romania
}

\begin{abstract}
Equipment operating in installations endangered by the occurrence of potentially explosive atmospheres have special features designed in order to make them suitable for operations in such areas. Equipment designed for use in potentially explosive atmospheres shall be placed on the EU market considering the provisions of the ATEX Directive 2014/34/EU and the harmonized European standards under this Directive. Even if equipment is placed on the EU market in accordance with ATEX Directive 2014/34/EU provisions, the special characteristics providing protection to explosion can be invalidated in installation design, erection, operation, inspection, maintenance or repairing phases. In order to prevent invalidation of explosion protection characteristics an important accent is placed on training and authorization of personnel involved in design, mounting, operation, inspection, maintenance or repairing of equipment/installations operating in potentially explosive atmospheres.
\end{abstract}

\section{Introduction}

Equipment intended to be used in potentially explosive atmospheres shall be designed, constructed and placed on the EU market considering the provisions of the ATEX Directive 2014/34/EU [1].

In this, the equipment shall be supplied together with some specific evidence to prove conformity to the requirements of ATEX Directive 2014/34/EU (declaration of conformity, instructions, certificate etc.) [2].

In all areas of activity, to provide quality products or services, the quality standards (i.e. ISO 9001, ISO 14001 etc.) require the use of qualified and competent human resources [3].

In this context, the manufacturer of equipment designed to operate in potentially explosive atmospheres must take care that the personnel involved in designing, fabrication and placing on the market of such products possess the required competencies and

\footnotetext{
Corresponding author: lucian.moldovan@insemex.ro
} 
knowledge so as these products comply with all the requirements of the applicable legislation and technical standards.

Even if equipment is provided in accordance with ATEX Directive 2014/34/EU provisions, the special characteristics providing protection to explosion can be invalidated during the different stages of an installation (design, erection, operation, inspection, maintenance or repairing) [4, 5].

To prevent invalidation of explosion protection characteristics an important role has the training and authorization of personnel involved in design, mounting, operation, inspection, maintenance or repairing of equipment/installations operating in potentially explosive atmospheres.

Also, the responsible persons for installations operating in potentially explosive areas that need to implement and maintain all the specific measures (both technical and organizational) required by the explosion protection document mentioned by Directive 1999/92/EC have an important role in preserving explosion protection characteristics [6].

The involvement of personnel training related to implementing and maintaining the specific measures to provide and preserve explosion protection is presented in Figure 1.

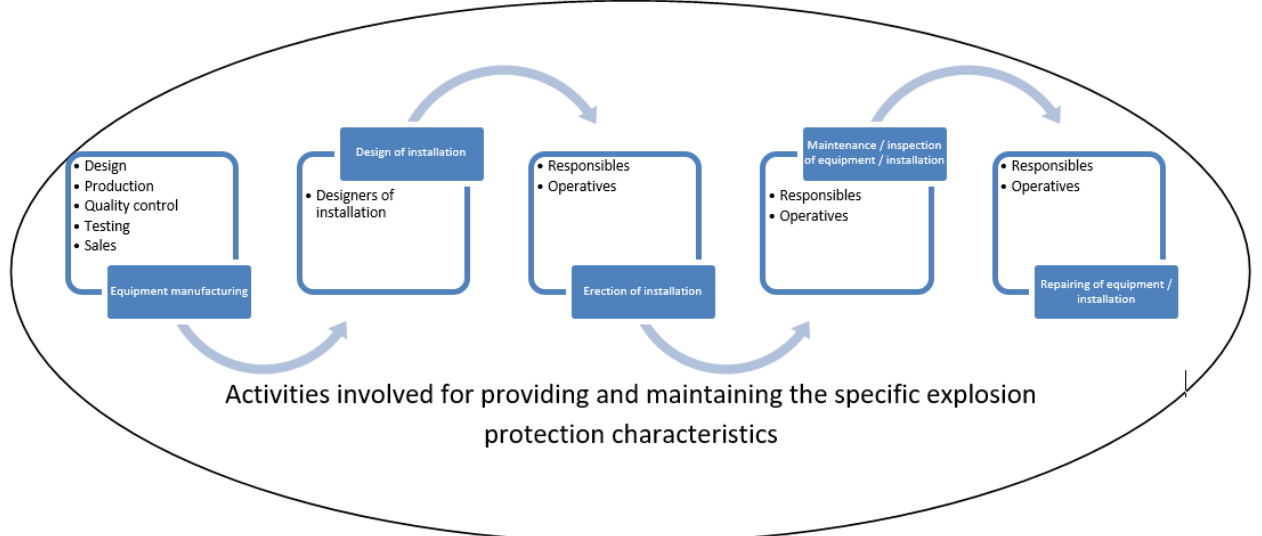

Fig. 1 Involvement of personnel training in activities related to implementing and maintaining the specific measures to provide and preserve explosion protection

\section{Specific requirements in relation to training of personnel performing specific activities related to equipment $/$ installations operating in areas classified as with potentially explosive atmospheres}

For the personnel that is involved in the manufacturing of equipment, components or protective systems for use in potentially explosive atmospheres, according the standard SR EN ISO/IEC 80079-34 the manufacturer shall ensure that all persons having an impact on Ex compliance receive appropriate training. People considered to have an impact on the final product may include those involved in the manufacturing, inspection, testing, supply up to those involved in sales, marketing etc. [7]

The design of the installation, selection of equipment, erection of installation, inspection and maintenance of installations must be carried out, according the provisions of SR EN 60079-14 and SR EN 60079-17, only by persons that received proper training on the specific types of protection and relevant activities, specific rules, regulations and norms and also on the general aspects of area classification. The persons shall be competent in the relevant type of work to be performed. Appropriate continuing education or training shall be undertaken by personnel on a regular basis to demonstrate competency over the new and 
continuously updated regulations, standards and technical prescriptions. Competency can be proved within specific training and assessment programs considering the national regulations, technical standards and/or specific user requirements $[8,9]$.

Repairing facilities shall possess adequately trained personnel for performing specific reparations related to equipment operating in potentially explosive atmospheres according the specific provisions of SR EN 60079-19. Repairing facilities have to nominate a competent person ('responsible person') within the management of the organization, that will have both authority and responsibility to ensure the compliance of the overhauled/repaired equipment to the certification status, previously agreed with the user of the equipment. The responsible person shall possess practical knowledge of the specific explosion protection standards and understanding of appropriate provisions in SR EN 60079-19. Also, the repair facility must have trained competent operatives, considering the specific type(s) of protection [10].

\section{Specific knowledge, skills and competencies of personnel involved in specific activities related to equipment/installations operating in potentially explosive atmospheres}

It is obvious that the personnel involved in specific activities related to equipment/installations operating in potentially explosive atmospheres shall possess adequate and specific knowledge, skills and competencies. These are in direct relation to the specific activities that a person has to perform.

The specific knowledge, skills and competencies of personnel involved in specific activities related to equipment/installations operating in potentially explosive atmospheres are described also in the specific standards.

In case of design, erection, selection, inspection and maintenance of equipment and operation of equipment/installations in potentially explosive atmospheres the following aspects should be observed:

Responsible persons (selection, erection, inspection and maintenance) [8, 9]

Responsible persons for the processes related to the selection, erection, inspection and maintenance of explosion protected equipment shall possess (and prove their competency), at least, the following:

- general knowledge in electrical engineering related to envisaged activities;

- $\quad$ ability to understand, read and assess technical engineering drawings;

- knowledge of practical aspects regarding the principles and techniques required for providing explosion protection;

- practical knowledge and comprehension regarding the prescriptions of relevant standards related to explosion protection;

- basic knowledge related to quality assurance (auditing principles, documentation, importance of measurement traceability and instrument calibration etc.).

Operatives/technicians (selection, erection, inspection and maintenance) $[8,9]$

Operatives/technicians shall possess (and prove their competency), to the extent required to perform specific activities, the following:

- understanding the main aspects related to explosion protection (general principles);

- understanding the main aspects related to the types of protection and marking (general principles);

- understanding the specific aspects in the design of the equipment that can influence the explosion protection concept; 
- understanding the certificates for Ex equipment/components and specific relevant parts of standards related to the activities to be performed;

- general knowledge regarding the inspection and maintenance requirements of SR EN 60079-17;

- knowledge related to the specific techniques to be involved in the selection and installation of equipment;

- understanding and knowledge related to the permit to work systems; and for safe isolation for preserving explosion protection.

- comprehensive understanding of the selection and mounting requirements of SR EN 60079-14 (in case of inspection and maintenance operations);

- general understanding of the repair and reclamation requirements of SR EN 60079-19 (in case of inspection and maintenance operations).

The personnel must be able to prove the competence in the use of technical documentation (with documentary evidence); production of reports (e.g. inspection reports); practical skills required for the mounting of equipment with relevant types of protection; and use and elaboration of information related to installation (records) [8, 9].

Designers (design and selection of explosion-proof equipment/installations) [8]

Designers shall possess, (and prove their competency), to the extent required to accomplish specific tasks, the following:

- knowledge of detailed aspects of general principles related to explosion protection;

- knowledge of the aspects (general) related to the types of protection and marking;

- detailed knowledge of the specific aspects in the design of the equipment that can influence the explosion protection concept;

- detailed information regarding the certificates content and also on the relevant parts of SR EN 60079-14;

- be aware of the practical skills needed for the mounting of equipment for the specific concepts (types) of protection;

- knowledge of the aspects (in detail) related to the permit to work systems; and for safe isolation for preserving explosion protection;

- detailed information on the specific techniques required in the selection and mounting of equipment according the provisions of SR EN 60079-14;

- understanding of general requirements for inspection and maintenance as specified in SR EN 60079-17.

The designers must be able to prove the competence in the production of technical documentation (with documentary evidence); practical skills required to elaborate and compile the relevant design details for the concepts of protection and systems involved; and update and elaborate the installation information (records) [8].

"Responsible persons" with responsibilities regarding the overhaul, repair and reclamation activities related to explosion protected equipment having specific types of protection, according SR EN 60079-19 shall possess, at least, the following [10]:

- knowledge of general requirements regarding the relevant and specific electrical and mechanical engineering at the craftsperson level (or above);

- practical understanding of explosion-protection principles and techniques;

- ability to understand, read and assess technical engineering drawings;

- familiarity with measurement functions, including practical metrology skills, to measure known quantities;

- practical knowledge and comprehension regarding the prescriptions of relevant standards related to explosion protection;

- basic knowledge related to quality assurance (also regarding measurement traceability and importance of instrument calibration etc.). 
Such persons have to limit their attributions to overhaul, repair and/or reclamation in their fields of competence and not to involve in modifications of the equipment characteristics that provide explosion protection without expert guidance [10].

Operatives, involved in repairing works (according SR EN 60079-19), have to possess, to the extent required to perform specific activities, the following [9]:

- understanding the main aspects related to the types of protection and marking (general principles);

- understanding the specific aspects in the design of the equipment that can influence the explosion protection concept;

- understanding of examination and testing as related to relevant parts SR EN 60079-19;

- ability to identify replacement parts and components authorized by the manufacturer;

- familiarity with the specific techniques to be involved in repairs referred to in SR EN 60079-19.

Responsible persons and operatives have to demonstrate they are competent and be able to provide evidence regarding the knowledge and skill requirements [10].

Operatives have to demonstrate they are competent and be able to provide evidence regarding the knowledge and skill requirements in relation with the equipment type and the type(s) of protection involved. They have to demonstrate they are competent in the use and availability of technical documentation; elaboration of job reports made available to the user and also in the use and elaboration of repair facility records [10].

The competency (of designers, responsible persons, operatives, technical persons with executive function etc.) must be verified (and attributed) at specific intervals in order to demonstrate (with sufficient evidence) that the person has the necessary skills to perform the specific work; possess the competence related to the specified range of activities demonstrated by relevant knowledge and understanding $[8,9,10]$.

\section{Authorization of personnel involved in specific activities related to equipment / installations operating in potentially explosive atmospheres in Romania}

In Romania, the specific regulation applying for specific activities related to equipment/installations operating in potentially explosive atmospheres is represented by Normative NEx 01-06/2007. By this regulation the capacity and capability of the National Institute for Research and Development in Mine Safety and Protection to Explosion (INSEMEX) is recognized, this being nominated to be the specific training provider for the personnel that perform specific activities related to equipment/installations operating in potentially explosive atmospheres (design, mounting, operation, inspection, maintenance, repairing etc.) [11].

This training is performed in the Department for Safety of Installations and Explosionproof Equipment and the technical group GANEx (technical Group of Attestation for compliance to the requirements of Normative NEx 01-06).

The training activity for the personnel involved in specific activities related to equipment/installations operating in potentially explosive atmospheres started before 1980 with the personnel from the mining facilities endangered by firedamp. It extended afterwards with the training activity for the personnel from other industries endangered by the occurrence of potentially explosive atmospheres (chemical, petrochemical, oil \& gas etc.). 
Training of personnel considers the aspects included in the technical standards for the different types of activities to be performed by specific personnel.

Authorization of personnel consists in two stages, one for specific training and one for examination. The authorization obtained after examination is valid for a period of three years and can be renewed for three years more before the expiring.

The electronic evidence of this training activity started in the middle of 2010 . From this point of view the number of persons that were trained and authorized at INSEMEX increased. For 2019 the considered information refers only to the first 5 months. This is presented in Figure 2.

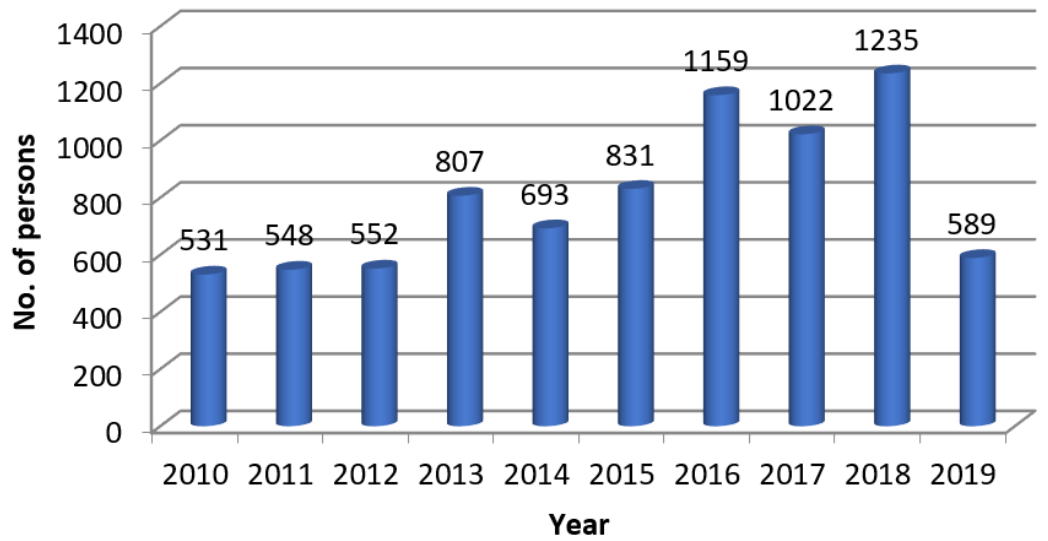

Fig. 2 Authorized personnel for specific activities related to equipment/installations operating in potentially explosive atmospheres

The personnel performing specific activities related to equipment/installations operating in potentially explosive atmospheres was authorized for the specific following activities: design, mounting/erection, putting in operation, use/operation, inspection, maintenance, repairing, control and service. Many of the authorized persons opted and prove their competence in more than one activity. The number of persons that were authorized for each specific activity, starting with the year 2011, is presented in Table 1.

Table 1. Number of persons authorized for each specific activity related to equipment/installations operating in potentially explosive atmospheres

\begin{tabular}{|l|c|c|c|c|c|c|c|c|c|}
\hline \multirow{4}{*}{\multicolumn{1}{|c|}{ Activity }} & \multicolumn{7}{|c|}{ Year } \\
\cline { 2 - 11 } & $\mathbf{2 0 1 1}$ & $\mathbf{2 0 1 2}$ & $\mathbf{2 0 1 3}$ & $\mathbf{2 0 1 4}$ & $\mathbf{2 0 1 5}$ & $\mathbf{2 0 1 6}$ & $\mathbf{2 0 1 7}$ & $\mathbf{2 0 1 8}$ & $\mathbf{2 0 1 9}$ \\
\cline { 2 - 11 } & \multicolumn{7}{|c|}{ Number of persons authorized for each specific activity } \\
\hline Design & 88 & 88 & 121 & 108 & 132 & 173 & 192 & 155 & 101 \\
\hline Mounting/Erection & 228 & 217 & 289 & 274 & 360 & 374 & 332 & 557 & 281 \\
\hline Putting in operation & 6 & 12 & 6 & 11 & 35 & 9 & 261 & 460 & 280 \\
\hline Use / Operation & 145 & 204 & 299 & 245 & 344 & 445 & 709 & 1414 & 678 \\
\hline Inspection & 16 & 23 & 30 & 21 & 44 & 65 & 390 & 746 & 402 \\
\hline $\begin{array}{l}\text { Maintenance and } \\
\text { service }\end{array}$ & 406 & 438 & 660 & 547 & 706 & 891 & 663 & 849 & 447 \\
\hline Repairing & 7 & 1 & 11 & 4 & 8 & 5 & 16 & 30 & 8 \\
\hline Control & 26 & 49 & 35 & 21 & 70 & 60 & 122 & 28 & 7 \\
\hline
\end{tabular}


Also, from this table one can observe that there was also an increase in the specific activities for which the personnel performing specific activities related to equipment/installations operating in potentially explosive atmospheres was authorized. This could be explained on one side by the increasing of the number of authorized persons. On other side, some activities are related one to another, for example mounting activity is related to the inspection activity (because after the mounting/erection of an equipment/installation an initial detailed inspection must be performed). But the main factors are represented by the significant increase of importance and impact at the level of companies that are performing specific activities related to equipment/installations operating in potentially explosive atmospheres (in order to have skilled, trained and competent personnel) and also the increase of requirements by the companies needing adequate services related to their equipment and installations operating in potentially explosive atmospheres.

\section{Conclusions}

The paper presented in its first part the importance and need for competent and trained personnel in the context of specific activities (design, erection, mounting, inspection, maintenance, repairing etc.) related to equipment/installations operating in potentially explosive atmospheres. It also presented the technical regulations and standards related to specific activities in this field and the specific requirements for the personnel performing these activities.

The next part presented the specific knowledge, skills and competencies the personnel performing specific activities related to equipment/installations operating in potentially explosive atmospheres shall possess in order to perform them in an adequate way.

The last part of the paper presented some specific aspects related to the training of personnel activity in Romania (related to equipment/installations operating in potentially explosive atmospheres) and at INSEMEX together with the specific Romanian applicable regulations. In this part were also presented some important factors that lead to the increase of the number of persons trained in this specific field.

\section{References}

1. T. Csaszar, S. Burian, M. Darie, C. Colda, A. Andriș, Annals of the University of Petrosani Electrical Engineering, Vol. 19, 63-70 (2017)

2. Directive 2014/34/EU (2014)

3. C. Dura, I. Drigă, C. Isac, EEMJ 16 (6), 1269-1274 (2017)

4. L. Moldovan, S. Burian, G.A. Găman, M. Părăian, M. Magyari, Proceedings of the 17th International Multidisciplinary Scientific Geoconference SGEM 2017 17, 531-538 (2017)

5. L. Moldovan, S. Burian, M. Magyari, M. Darie, D.Fotău, EEMJ 16 (6), 1309-1316 (2017)

6. Directive 1999/92/EC (1999)

7. Standard SR EN 80079-34 (2012)

8. Standard SR EN 60079-14 (2014)

9. Standard SR EN 60079-17 (2014)

10. Standard SR EN 60079-19 (2011)

11. Normative NEx 01-06/2007 (2007) 